\title{
PERBEDAAN TINGKAT KEPARAHAN PSORIASIS PADA PASIEN PSORIASIS DENGAN DAN TANPA FOKAL INFEKSI
}

\section{DIFFERENCE OF PSORIASIS AREA SEVERITY INDEX BETWEEN PATIENTS WITH AND WITHOUT FOCAL INFECTIONS}

\author{
Caroline Astrid $^{1}$, Ismiralda Oke Putranti ${ }^{1,2}$, Kurniasih Dwi Purwanti ${ }^{3}$ \\ ${ }^{1}$ Fakultas Kedokteran, Universitas Jenderal Soedirman, Purwokerto, Indonesia \\ ${ }^{2}$ Departemen Ilmu Kesehatan Kulit dan Kelamin, RSUD Prof. Dr. Margono Soekarjo, \\ Purwokerto, Indonesia \\ ${ }^{3}$ Klinik Psikologi, RSUD Dr. R. Goeteng Taroenadibrata, Purbalingga, Indonesia
}

\begin{abstract}
ABSTRAK
Psoriasis adalah penyakit kulit yang sering dijumpai, kronik, tidak menular, terjadi akibat kelainan kompleks pada pertumbuhan dan diferensiasi epidermal serta abnormalitas multipel dari biokimia, imunologi, dan vaskular. Salah satu faktor risiko psoriasis adalah fokal infeksi. Penelitian ini bertujuan mengetahui perbedaan tingkat keparahan psoriasis pada pasien psoriasis dengan dan tanpa disertai fokal infeksi di RSUD Prof. Dr. Margono Soekarjo, Purwokerto. Penelitian ini merupakan penelitian analitik observasional dengan pendekatan cross-sectional. Subjek penelitian adalah 40 pasien psoriasis yang berobat di Poli Kulit dan Kelamin RSUD Prof. Dr. Margono Soekarjo pada bulan November hingga Desember 2017 yang memenuhi kriteria inklusi dan eksklusi. Tingkat keparahan psoriasis diukur menggunakan Psoriasis Area Severity Index (PASI). Analisis data menggunakan independent $t$-test. Rata-rata tingkat keparahan psoriasis pada pasien dengan fokal infeksi 28,63 dan tanpa fokal infeksi 17,29, dengan jenis fokal infeksi didapatkan fokal infeksi intraoral $(47,5 \%)$ dan genital $(2,5 \%)$. Perbedaan tingkat keparahan psoriasis pada pasien dengan dan tanpa fokal infeksi didapatkan $\mathrm{p}=0,000(\mathrm{p}<0,05)$. Terdapat perbedaan signifikan tingkat keparahan psoriasis pada pasien dengan dan tanpa fokal infeksi.
\end{abstract}

Kata kunci: fokal infeksi, psoriasis, tingkat keparahan

\begin{abstract}
Psoriasis is a common, chronic, noncontagious skin disease, caused by complex abnormal epidermal growth with multiple abnormality of biochemistry, immunology, and vascular. One of psoriasis risk factors is focal infection. This study was an analytical study with cross-sectional approach, to establish the difference of Psoriasis Area Severity Index (PASI) in patients with and without focal infections in Prof. Dr. Margono Soekarjo Public Hospital, Purwokerto. Subjects of this study were psoriasis outpatients in Dermatology and Venereology Clinic in November until December 2017. Forty subjects who fulfilled the inclusion and exclusion criteria were measured using PASI. This study showed the average of the PASI on patients with focal infections was 28.63
\end{abstract}


and without focal infections was 17.29, with types of the focal infection were intraoral focal infections (47,5\%) and genital focal infections (2,5\%). The difference of PASI between patients with and without focal infections was significant with $\mathrm{p}=0,000(\mathrm{p}<0,05)$. There is a significant difference on degree of psoriasis between patients with and without focal infections.

Keywords: focal infection, psoriasis, severity index

\section{Penulis korespondensi:}

Caroline Astrid

Fakultas Kedokteran, Universitas Jenderal Soedirman

Jalan Dr. Gumbreg No. 1, Purwokerto, Indonesia

Email: carolineastrid@outlook.com

\section{PENDAHULUAN}

Psoriasis adalah penyakit kulit yang sering dijumpai, bersifat kronik dan tidak menular dengan penyebab pasti belum jelas. Psoriasis merupakan penyakit inflamasi pada kulit yang bersifat kronis, menetap, dan residif akibat kelainan yang kompleks pada pertumbuhan dan diferensiasi epidermal serta abnormalitas multipel dari biokimia, imunologi, dan vaskular (Gayatri dan Ervianti, 2014). Kelainan utama pada psoriasis adalah hiperproliferasi oleh proses keratinisasi yang lebih cepat dari biasanya (World Health Organization, 2016).

Insidensi psoriasis tersebar di seluruh dunia. Psoriasis terjadi pada pria dan wanita dari seluruh kelompok usia, etnis, dan semua negara. Diperkirakan 3\% penduduk dunia menderita psoriasis dengan perbandingan 1:1 pada pria dan wanita dewasa (World Health Organization, 2016). Di Amerika Serikat terdapat 150.000 kasus baru psoriasis yang ditemukan, yaitu setara dengan hampir 2,2\% dari populasi Amerika Serikat, sedangkan data prevalensi psoriasis secara nasional di Indonesia masih belum diketahui (Gudjonsson dan Elder, 2012). Di Rumah Sakit Umum Pusat Nasional Dr. Cipto Mangunkusumo, Jakarta, dari tahun 1997 hingga 2001, angka kejadian psoriasis mencapai 2,6\% (Jacoeb, 2003). Berdasarkan catatan bagian Rekam Medik Rumah Sakit Umum Daerah Prof. Dr. Margono Soekarjo, Purwokerto, total kunjungan pasien psoriasis pada tahun 2016 mencapai 562 kunjungan dan bulan Januari hingga Agustus 2017 mencapai 705 kunjungan (Ernawati, 2017).

Psoriasis merupakan suatu penyakit keturunan dan diduga berhubungan dengan sistem imun dan respon peradangan. Tanda utama dari psoriasis adalah hiperplasia sel epidermis. Tanda klinis psoriasis selain penampakan dan distribusinya, ada tanda klinis khas pada psoriasis, yaitu fenomena tetesan lilin, tanda Auspitz, fenomena Koebner, serta rasa gatal dan nyeri yang bersifat lokal pada papul dan plak. Fenomena tetesan lilin terjadi ketika penggoresan skuama utuh dengan menggunakan pinggir gelas objek, lalu terjadi perubahan warna lebih putih menyerupai tetesan lilin. Tanda Auspitz adalah adanya darah yang keluar ketika lesi diangkat berupa pinpoint bleeding, sedangkan fenomena Koebner adalah lesi psoriasis yang diinduksi oleh adanya trauma pada kulit (Gudjonsson dan Elder, 2012; Nast et al, 2012; Weigle, 2013). 
Salah satu alat ukur untuk menilai keparahan lesi psoriasis adalah Psoriasis Area Severity Index (PASI). Penilaian PASI pertama kali diformulasikan oleh Fredricksson dan Pettersson dan sering dipakai dalam evaluasi klinis. Nilai PASI berkisar antara 0-72. Angka penghitungan PASI berkisar antara 0 hingga 72 dengan peningkatan sebesar 0,1 unit sehingga banyak dipakai untuk pharmacy research setting. PASI dapat dikelompokkan menjadi ringan (PASI <7), sedang (PASI 7-12), dan berat (PASI > 12) (Budiastuti, 2011; Picciani et al, 2013).

Penyebab psoriasis sampai saat ini masih belum jelas dan yang sudah diketahui adalah faktor-faktor yang memengaruhi timbulnya psoriasis berdasarkan data epidemiologi, antara lain bangsa, daerah, iklim, keturunan, dan faktor lain. Bangsa kulit putih lebih banyak mengalami psoriasis daripada kulit berwarna, orang yang tinggal di daerah dingin lebih banyak mengalami psoriasis, pada saat iklim hujan lebih sering ditemukan kasus psoriasis, secara faktor keturunan psoriasis diturunkan secara autosomal dominan, serta stres dapat memperberat psoriasis (Gudjonsson dan Elder, 2012; Siregar, 2015).

Salah satu faktor risiko psoriasis yang penting adalah fokal infeksi. Teori fokal infeksi yang muncul pada abad ke-20 menyatakan bahwa penyakit sistemik dapat disebabkan oleh mikroorganisme yang berkembang dari fokal infeksi, misalnya sinus, adenoid, tonsil, gigi, traktus genitourinaria, kandung empedu, dan ginjal. Fokal infeksi adalah tempat terakumulasinya mikroorganisme dan biasanya tanpa gejala atau asimptomatik. Respons infeksi mungkin disebabkan oleh penyebaran mikroorganisme dari fokal infeksi. Fokal infeksi pada penyakit sistemik diduga memengaruhi proses inflamasi, seperti artritis, neuritis, endokarditis, pankreatitis, pneumonia, asma, penyakit Hodgkin, dan lain-lain (Brzewski et al, 2013). Fokal infeksi terutama pada saluran pernapasan atas diketahui sebagai pencetus psoriasis pada $44 \%$ pasien. Hipotesisnya adalah toksin Streptococcus -hemolyticus berperan sebagai superantigen yang dapat mengaktivasi sel T. Superantigen Staphylococcus juga ditemukan pada 17\% pasien psoriasis yang mengalami peningkatan keparahan penyakitnya (Khanna dan Kumar, 2015).

Penelitian tentang perbedaan tingkat keparahan psoriasis pada pasien psoriasis dengan dan tanpa disertai fokal infeksi di RSUD Prof. Dr. Margono Soekarjo belum pernah diteliti. Berdasarkan fakta tersebut, maka penelitian ini disusun dengan tujuan mengetahui perbedaan tingkat keparahan psoriasis dengan atau tanpa fokal infeksi.

\section{METODE PENELITIAN}

Penelitian ini menggunakan rancangan analitik observasional dengan pendekatan crosssectional. Pengambilan sampel menggunakan nonprobability sampling dengan consecutive sampling. Sampel adalah bagian dari populasi terjangkau, yaitu pasien psoriasis yang terdaftar sebagai pasien di Poli Kulit dan Kelamin RSUD Prof. Dr. Margono Soekarjo, berada di Kabupaten Banyumas pada bulan November hingga Desember 2017, dan telah memenuhi kriteria inklusi dan eksklusi. Kriteria inklusi sampel penelitian ini antara lain pasien yang terdiagnosis psoriasis melalui anamnesis, pemeriksaan fisik, dan pemeriksaan penunjang oleh dokter spesialis kulit dan kelamin di Poli Kulit dan Kelamin RSUD Prof. Dr. Margono Soekarjo serta pasien yang bersedia menjadi responden penelitian dengan menandatangani lembar kesediaan menjadi responden penelitian. Kriteria eksklusi sampel penelitian ini antara lain pasien psoriasis yang menderita penyakit kulit lain (dermatitis, dermatofitosis, dan infestasi parasit), pasien psoriasis yang menderita penyakit lain (kanker, hipertensi, jantung koroner, diabetes melitus, penyakit hati berat, dan HIV), pasien psoriasis yang menderita gangguan psikiatri (ansietas dan depresi), pasien psoriasis yang memiliki indeks massa

tubuh lebih dari $30 \mathrm{~kg} / \mathrm{m}^{2}$ (obesitas), pasien psoriasis yang memiliki kebiasaan merokok dan mengonsumsi alkohol serta pasien psoriasis yang mengonsumsi 
obat-obatan beta blocker, litium, obat-obatan antimalaria, obat antiinflamasi nonsteroid dan steroid tanpa pengawasan dokter, dan kontrasepsi oral.

Besar sampel sebanyak 40 yang terbagi menjadi 20 sampel psoriasis dengan fokal infeksi dan 20 sampel psoriasis tanpa fokal infeksi. Data yang digunakan adalah data primer. Alat pengumpulan data yang digunakan, yaitu lembar karakteristik responden dan nilai Psoriasis Area Severity Index (PASI). Identifikasi tingkat keparahan psoriasis dengan PASI paling sering digunakan untuk mendiagnosis dan mengukur tingkat keparahan psoriasis. PASI berkisar antara 0-72 dinilai oleh dokter spesialis kulit dan kelamin menggunakan salah satu kalkulator PASI, yaitu PASI Calculator 1.7.1 yang dapat diakses melalui www.pasi.corti.li. Dalam perhitungan PASI terdapat empat area utama yang diukur: kepala, tubuh, ekstremitas atas, dan ekstremitas bawah, berdasarkan 10\%, 20\%, 30\%, dan 40\% dari total area tubuh (Budiastuti, 2011). Pasien psoriasis diwawancarai untuk mengetahui riwayat fokal infeksi berupa fokal infeksi intraoral, saluran pernapasan atas, telinga, hidung, tenggorokan, dan genital kemudian diperiksa oleh dokter spesialis kulit dan kelamin lalu dikonsultasikan ke dokter spesialis bidang terkait temuan fokal infeksi pada pasien untuk didiagnosis lebih lanjut. Analisis univariat dilakukan untuk memeroleh gambaran dari tingkat keparahan psoriasis, jenis fokal infeksi, dan fokal infeksi pada tiap tingkat keparahan.

\section{HASIL DAN PEMBAHASAN}

Data primer responden berupa riwayat fokal infeksi didapatkan melalui wawancara untuk pengisian lembar karakteristik responden dan nilai PASI dinilai oleh dokter spesialis kulit dan kelamin RSUD Prof. Dr. Margono Soekarjo.

a. Analisis Univariat

Tabel I. Distribusi kelompok usia responden

\begin{tabular}{ccc}
\hline Kelompok Usia (tahun) & Jumlah $(\mathbf{N})$ & Persentase $(\%)$ \\
\hline$\leq 20$ & 6 & 15,00 \\
$21-30$ & 6 & 15,00 \\
$31-40$ & 5 & 12,50 \\
$41-50$ & 9 & 22,50 \\
$51-60$ & 8 & 20,00 \\
$61-70$ & 5 & 12,50 \\
$71-80$ & 1 & 2,50 \\
\hline Total & 40 & 100,00 \\
\hline
\end{tabular}

Sumber: data primer terolah

Tabel I menunjukkan bahwa responden paling banyak berusia dari rentang 41-50 tahun, yaitu sebanyak 9 orang $(22,50 \%)$ dan paling sedikit berusia dari rentang 71-80 tahun, yaitu 1 orang $(2,50 \%)$. 
Tabel II. Karakteristik usia responden

\begin{tabular}{cc}
\hline Karakteristik Usia & Nilai (tahun) \\
\hline Rata-rata & 41,93 \\
Standar Deviasi (SD) & 18,06 \\
Usia Termuda & 8 \\
Usia Tertua & 73 \\
\hline
\end{tabular}

Sumber: data primer terolah

Berdasarkan Tabel II, rata-rata usia responden penelitian adalah 41,93 tahun, standar deviasi usia responden adalah 18,06 tahun, usia termuda responden adalah 8 tahun, dan usia tertua responden adalah 73 tahun. Hal ini sesuai dengan hasil penelitian Al-Hamamy et al (2014) pada 113 responden yang menyebutkan rata-rata usia respondennya adalah 41,04 tahun dengan standar deviasi 10,25 tahun. Selain itu juga sesuai dengan penelitian Herédi et al (2013) yang dilakukan di Hungaria. Rata-rata usia responden dari total 377 pasien psoriasis yang terlibat dalam penelitian tersebut adalah 50,5 tahun pada waktu pelaksanaan penelitian. Hasil ini juga sesuai dengan penelitian Hossler et al (2013) di Inggris yang menyatakan bahwa rata-rata usia responden psoriasis dari 34 responden dalam penelitian tersebut adalah 49,8 tahun.

Prevalensi psoriasis lebih tinggi pada usia dewasa $(0,91-8,5 \%)$ daripada anak-anak (02,1\%) dengan dua puncak insidensi, yaitu 30-39 dan 60 tahun. Prevalensi psoriasis juga berbeda pada setiap negara karena perbedaan pola geografis. Prevalensi lebih sedikit di negara yang lebih dekat dengan ekuator bumi daripada negara yang lebih jauh dengan ekuator bumi karena efek paparan radiasi ultraviolet dan tampilan klinis psoriasis. Paparan radiasi ultraviolet pada anak-anak lebih banyak daripada dewasa. Hal ini menjelaskan lebih sedikitnya responden berusia anak-anak daripada dewasa dalam penelitian ini (Di Meglio et $a l, 2014)$.

Menurut penelitian Ceovic et al (2013), hormon perempuan secara signifikan memengaruhi perubahan biologis dan imunologis pada kulit. Tingkat keparahan psoriasis pada pasien perempuan bisa berubah-ubah sesuai perubahan hormonal karena psoriasis terjadi lebih sering atau lebih parah pada pubertas dan juga menopause. Hal ini juga sesuai dengan hasil analisis distribusi usia responden, bahwa jumlah responden paling banyak adalah pada rentang usia 41-50 tahun, yaitu sebanyak 9 orang dan rentang usia 51-60 tahun, yaitu sebanyak 8 orang.

Tabel III. Distribusi awitan psoriasis

\begin{tabular}{ccc}
\hline Kelompok Usia (tahun) & Jumlah $(\mathbf{N})$ & Persentase $(\%)$ \\
\hline$\leq 20$ & 10 & 25,00 \\
$21-30$ & 9 & 22,50 \\
$31-40$ & 6 & 15,00 \\
$41-50$ & 5 & 12,50 \\
$51-60$ & 6 & 15,00 \\
$61-70$ & 3 & 7,50 \\
$71-80$ & 1 & 2,50 \\
\hline Total & 40 & 100,00 \\
\hline
\end{tabular}

Sumber: data primer terolah 
Tabel III menunjukkan bahwa awitan psoriasis paling banyak adalah kelompok usia di bawah 20 tahun, yaitu sebanyak 10 orang $(25,00 \%)$ dan awitan psoriasis paling sedikit adalah kelompok usia 71-80 tahun, yaitu sebanyak 1 orang $(2,50 \%)$.

Tabel IV. Karakteristik awitan psoriasis

\begin{tabular}{cc}
\hline Karakteristik Awitan Psoriasis & Nilai (tahun) \\
\hline Rata-rata & 34,03 \\
Standar Deviasi (SD) & 18,69 \\
Awitan Termuda & 0 \\
Awitan Tertua & 72 \\
\hline
\end{tabular}

Sumber: data primer terolah

Berdasarkan Tabel IV, rata-rata awitan psoriasis pada responden penelitian adalah 34,03 tahun, standar deviasi awitan psoriasis pada responden penelitian adalah 18,69 tahun, awitan termuda psoriasis pada responden penelitian adalah 0 tahun ( 3 bulan), dan awitan tertua psoriasis pada responden penelitian adalah 72 tahun.

Karakteristik awitan psoriasis dini (early onset, $\leq 40$ tahun) dan awitan psoriasis lambat (late onset, $>40$ tahun) disajikan pada Tabel V.

Tabel V. Karakteristik awitan psoriasis dini dan lambat

\begin{tabular}{cccccc}
\hline Awitan Psoriasis & Jumlah (N) & $\begin{array}{c}\text { Rata-rata } \\
\text { (tahun) }\end{array}$ & $\begin{array}{c}\text { SD } \\
\text { (tahun) }\end{array}$ & $\begin{array}{c}\text { Min. } \\
\text { (tahun) }\end{array}$ & $\begin{array}{c}\text { Maks. } \\
\text { (tahun) }\end{array}$ \\
\hline Awitan dini & 25 & 21,20 & 11,258 & 0 & 39 \\
Awitan lambat & 15 & 54,20 & 9,367 & 42 & 72 \\
\hline
\end{tabular}

Sumber: data primer terolah

Berdasarkan Tabel V, responden dengan awitan dini psoriasis ada sebanyak 25 orang dengan rata-rata 21,20 tahun, standar deviasi 11,258 tahun, awitan dini termuda adalah 0 tahun ( 3 bulan), dan awitan dini tertua adalah 39 tahun. Responden dengan awitan lambat psoriasis ada sebanyak 15 orang dengan rata-rata 54,20 tahun, standar deviasi 9,367 tahun, awitan lambat termuda adalah 42 tahun, dan awitan lambat tertua adalah 72 tahun. Hal ini sesuai dengan penelitian Herédi et al (2013) yang dilakukan di Hungaria. Penelitian tersebut menyatakan bahwa proposi responden psoriasis dengan awitan dini adalah 255 dari 377 responden $(67,6 \%)$ dan awitan lambat adalah 122 dari 377 responden $(32,4 \%)$. Rata-rata psoriasis awitan dini dalam penelitian tersebut adalah 24 tahun dengan standar deviasi 10,6 tahun, sedangkan rata-rata psoriasis awitan lambat adalah 53 tahun dengan standar deviasi 7,5 tahun.

Awitan psoriasis biasanya muncul sebelum usia 25-30 tahun, tetapi ada puncak kedua awitan psoriasis, yaitu pada usia 50-60 tahun. Sekitar 75\% kasus psoriasis merupakan awitan psoriasis sebelum usia 40 tahun (Higgins, 2017). Hal ini sesuai dengan hasil penelitian ini bahwa responden dalam penelitian ini lebih banyak yang mengalami psoriasis awitan dini daripada awitan lambat. 
Pembagian psoriasis berdasarkan awitannya terbagi menjadi psoriasis tipe 1 (early onset, $\leq 40$ tahun) yang biasanya berhubungan dengan riwayat penyakit keluarga dan berkaitan dengan HLA-Cw0602 dan psoriasis tipe 2 yang biasanya muncul setelah usia 40 tahun (Di Meglio et al, 2014).

Tabel VI. Distribusi jenis kelamin responden

\begin{tabular}{ccc}
\hline Jenis Kelamin & Jumlah $(\mathbf{N})$ & Persentase (\%) \\
\hline Laki-laki & 13 & 32,50 \\
Perempuan & 27 & 67,50 \\
\hline Total & 40 & 100,00 \\
\hline
\end{tabular}

Sumber: data primer terolah

Tabel VI menunjukkan bahwa responden berjenis kelamin laki-laki, yaitu sebanyak 13 orang $(32,50 \%)$ lebih sedikit daripada responden berjenis kelamin perempuan, yaitu sebanyak 27 orang $(67,50 \%)$.

Tabel VII. Distribusi tipe psoriasis

\begin{tabular}{ccc}
\hline Tipe Psoriasis & Jumlah $(\mathbf{N})$ & $\begin{array}{c}\text { Persentase } \\
(\mathbf{\%})\end{array}$ \\
\hline Psoriasis vulgaris & 24 & 60,00 \\
Psoriasis guttata & 8 & 20,00 \\
Sebopsoriasis & 2 & 5,00 \\
Zsoriasis pustulosa generalisata Von & 2 & 5,00 \\
Zumbusch & 3 & 7,50 \\
Eritroderma psoriatika & 1 & 2,50 \\
Unspecified psoriasis & 40 & 100,00 \\
\hline Total & &
\end{tabular}

Sumber: data primer terolah

Berdasarkan Tabel VII, tipe psoriasis responden paling banyak adalah psoriasis vulgaris, yaitu 24 orang $(60,00 \%)$ dan paling sedikit adalah unspecified psoriasis, yaitu 1 orang $(2,50 \%)$.

Tabel VIII. Rata-rata nilai PASI pasien psoriasis dengan dan tanpa fokal infeksi

\begin{tabular}{ccccc}
\hline Kelompok & Jumlah $(\mathbf{N})$ & Rata-rata PASI & PASI Min. & $\begin{array}{c}\text { PASI } \\
\text { Maks. }\end{array}$ \\
\hline Dengan fokal infeksi & 20 & 28,63 & 14,5 & 38,1 \\
Tanpa fokal infeksi & 20 & 17,29 & 3,3 & 34,9 \\
\hline
\end{tabular}

Sumber: data primer terolah

Tabel VIII menunjukkan bahwa rata-rata nilai PASI pada pasien psoriasis dengan fokal infeksi adalah 28,63 dan pasien psoriasis tanpa fokal infeksi adalah 17,29, nilai PASI minimum pada pasien dengan fokal infeksi adalah 14,5 dan tanpa fokal infeksi adalah 3,3, 
nilai PASI maksimum pada pasien dengan fokal infeksi adalah 38,1 dan tanpa fokal infeksi adalah 34,9 .

Tabel IX. Fokal infeksi pada tiap tingkat keparahan psoriasis

\begin{tabular}{|c|c|c|c|}
\hline $\begin{array}{c}\text { Tingkat } \\
\text { Keparahan }\end{array}$ & Jumlah (N) & $\begin{array}{c}\text { Dengan Fokal } \\
\text { Infeksi } \\
(\mathrm{N}) \\
\end{array}$ & $\begin{array}{c}\text { Tanpa Fokal Infeksi } \\
\text { (N) }\end{array}$ \\
\hline Ringan & 3 & 0 & 3 \\
\hline$($ PASI < 7) & $(7,50 \%)$ & $(0,00 \%)$ & $(100,00 \%)$ \\
\hline Sedang & 3 & 0 & 3 \\
\hline (PASI 7-12) & $(7,50 \%)$ & $(0,00 \%)$ & $(100,00 \%)$ \\
\hline Berat & 34 & 20 & 14 \\
\hline$(\mathrm{PASI}>12)$ & $(85,00 \%)$ & $(58,82 \%)$ & $(41,18 \%)$ \\
\hline
\end{tabular}

Sumber: data primer terolah

Tabel IX menunjukkan responden dalam penelitian ini dengan tingkat keparahan ringan sebanyak 3 orang (7,50\%) (0\% dengan fokal infeksi dan 100\% tanpa fokal infeksi), tingkat keparahan sedang sebanyak 3 orang $(7,50 \%)$ (0\% dengan fokal infeksi dan $100 \%$ tanpa fokal infeksi), dan tingkat keparahan berat sebanyak 34 orang $(85 \%)(58,82 \%$ dengan fokal infeksi dan 41,18\% tanpa fokal infeksi).

Tingkat keparahan psoriasis beragam karena dipengaruhi oleh faktor genetik, endokrin, infeksi, obat-obatan, dan kebiasaan atau gaya hidup. Orang dengan psoriasis tipe 1 biasanya psoriasis yang diderita lebih berat daripada psoriasis tipe 2 (Higgins, 2017). Orang dengan hormon estrogen rendah dapat menstimulasi semakin beratnya psoriasis (Ceovic et al, 2013). Obat-obatan (drug-induced psoriasis), misalnya beta bloker, litium, obat-obatan antimalaria (klorokuin), obat antiinflamasi nonsteroid atau nonsteroidal antiinflammatory drugs (NSAIDs), dan withdrawal dari kortikosteroid sediaan topikal, juga dapat menimbulkan psoriasis akibat efek rebound atau flare-up (Jain, 2012; Higgins, 2017). Penggunaan kontrasepsi oral juga dapat memengaruhi keparahan psoriasis. Kontrasepsi oral dapat memperparah psoriasis pada beberapa pasien dan memperbaiki psoriasis pada pasien lainnya (Berth-Jones, 2013). Gaya hidup, misalnya stres psikologis, merokok, konsumsi alkohol, dan obesitas dapat memengaruhi keparahan psoriasis (Higgins, 2017).

Pada penelitian ini, faktor penggunaan obat-obatan dan gaya hidup telah diterapkan pada kriteria eksklusi sehingga hasil pengukuran tingkat keparahan psoriasis menjadi lebih homogen, cenderung lebih banyak pada tingkat keparahan berat (PASI > 12), yaitu sebanyak 34 orang $(85,00 \%)$.

Hal ini sesuai dengan hasil penelitian Picciani et al (2013) yang menyatakan responden dengan tingkat keparahan ringan sebanyak 82 orang (52\%), terdiri dari 17 orang (21\%) dengan kandidiasis oral dan 65 orang (79\%) tanpa kandidiasis oral, tingkat keparahan sedang sebanyak 17 orang (12\%) terdiri dari 3 orang (18\%) dengan kandidiasis oral dan 14 orang $(82 \%)$ tanpa kandidiasis oral, tingkat keparahan berat sebanyak 41 orang $(36 \%)$ terdiri dari 17 orang (42\%) dengan kandidiasis oral dan 24 orang (58\%) tanpa kandidiasis oral. 
Tabel X. Distribusi jenis fokal infeksi

\begin{tabular}{ccc}
\hline Jenis Fokal Infeksi & Jumlah $(\mathbf{N})$ & Persentase (\%) \\
\hline Intraoral & 19 & 47,50 \\
Genital & 1 & 2,50 \\
\hline Total & 20 & 50,00 \\
\hline
\end{tabular}

Sumber: data primer terolah

Tabel X menunjukkan 19 orang responden (47,5\%) memiliki fokal infeksi intraoral dan 1 orang responden $(2,5 \%)$ memiliki fokal infeksi genital, dan sisanya tidak memiliki fokal infeksi. Fokal infeksi intraoral antara lain karies gigi dan kandidiasis oral. Fokal infeksi genital, yaitu bakterial vaginosis.

Fokal infeksi intraoral dapat disebabkan oleh infeksi organisme, seperti bakteri, jamur, protozoa, dan virus. Karies gigi merupakan fokal infeksi intraoral yang paling banyak terjadi dan merupakan sebab utama gigi tanggal pada hampir seluruh populasi. Karies gigi merupakan penyakit infeksi yang disebabkan oleh bakteri intraoral, terutama Streptococcus mutans dan Lactobacillus. Sebanyak 60-90\% anak-anak usia sekolah dan hampir 100\% orang dewasa memiliki kavitas gigi di seluruh dunia. Penyakit periodontal berat terdapat pada $15-20 \%$ orang dewasa usia 35-44 tahun. Sekitar 30\% orang berusia 65 hingga 74 tahun tidak memiliki gigi. Faktor risiko penyakit intraoral antara lain diet tidak sehat, perilaku merokok, konsumsi alkohol berlebihan, dan kebersihan mulut tidak terjaga. Fokal infeksi intraoral berhubungan dengan implikasi lokal (gigi tanggal) atau sistemik (Santosh et al, 2017).

Fokal infeksi lain yang ditemukan dalam penelitian ini adalah fokal infeksi genital, yaitu bakterial vaginosis. Menurut Hay (2014), bakterial vaginosis adalah penyakit vagina yang paling sering menyebabkan keluarnya sekret abnormal pada perempuan. Bakterial vaginosis disebabkan oleh pengurangan flora normal Lactobacillus dan pertumbuhan berlebih bakteri anaerob vagina yang menyebabkan perubahan $\mathrm{pH}$ vagina menjadi lebih basa. Organisme yang biasanya ditemukan pada bakterial vaginosis adalah Gardnerella vaginalis.

Beberapa infeksi dapat menjadi pencetus psoriasis. Penelitian Igawa et al (2011) menyatakan bahwa infeksi gigi dianggap sebagai faktor penting penyebab psoriasis. Kandidiasis oral juga disebutkan menjadi salah satu pemicu awitan dan eksaserbasi psoriasis. Pada saliva pasien psoriasis ditemukan jamur Candida sp. (Picciani et al, 2013). Infeksi Streptococcus sp. pada tenggorokan merupakan faktor penting. Periodontitis juga disebutkan meningkatkan risiko psoriasis (World Health Organization, 2016).

Tabel XI. Distribusi tipe psoriasis

\begin{tabular}{ccc}
\hline Tipe Psoriasis & Jumlah $(\mathbf{N})$ & Persentase (\%) \\
\hline Psoriasis vulgaris & 24 & 60,00 \\
Psoriasis guttata & 8 & 20,00 \\
Sebopsoriasis & 2 & 5,00 \\
Psoriasis pustulosa generalisata & & \\
Von Zumbusch & 2 & 5,00 \\
Eritroderma psoriatika & 3 & 7,50 \\
Unspecified psoriasis & 1 & 2,50 \\
\hline Total & 40 & 100,00 \\
\hline
\end{tabular}

Sumber: data primer terolah 
Tabel XI menunjukkan tipe psoriasis dengan responden terbanyak adalah psoriasis vulgaris, yaitu 24 orang (60\%). Hal ini sesuai dengan hasil penelitian Brzewski et al (2013), yaitu sebanyak 77 dari 101 responden $(76,23 \%)$ menderita psoriasis vulgaris atau plaquetype psoriasis. Hal ini sesuai dengan hasil penelitian Brzewski et al (2013), yaitu sebanyak 77 dari 101 responden $(76,23 \%)$ menderita psoriasis vulgaris atau plaque-type psoriasis.

Psoriasis vulgaris terjadi pada $85-90 \%$ pasien psoriasis dan merupakan tipe psoriasis paling umum dan ditandai dengan bentuk oval atau tidak beraturan, merah, berbatas tegas, dan dengan peninggian tertutup oleh skuama keperakan. Plak kebanyakan terdapat pada ekstensor siku dan lutut, kulit kepala, dan punggung bawah, tetapi bisa juga terdapat pada semua area tubuh, dan biasanya dengan distribusi simetris. Ukuran lesi bervariasi dari pinpoint hingga confluent. Lesi besar $(>3 \mathrm{~cm}$, tebal $>0,75 \mathrm{~cm})$, berbatas tegas, plak merah dengan skuama keperakan. Lesi kecil $(<3 \mathrm{~cm}$, tebal $<0,75 \mathrm{~cm})$, berwarna pink dengan skuama halus, dan berbatas tegas atau menyatu dengan kulit sekitar (Di Meglio et al, 2014).

Tipe psoriasis terbanyak kedua setelah psoriasis vulgaris dalam penelitian ini adalah psoriasis guttata, yaitu sebanyak 8 orang $(20,00 \%)$. Psoriasis guttata (eruptif) merupakan psoriasis berbentuk seperti tetesan (1-10 mm), papul warna kemerahan, biasanya dengan skuama halus, dan predileksi utamanya di badan dan anggota gerak atas. Psoriasis guttata biasanya disertai dengan adanya riwayat infeksi saluran pernapasan atas oleh Streptococcus beta-hemolitikus grup A (Bejarano dan Valdecantos, 2013).

b. Analisis Bivariat

Berikut adalah tabel hasil uji statistik untuk menilai perbedaan tingkat keparahan psoriasis kelompok dengan dan tanpa fokal infeksi pada seluruh responden.

Tabel XII. Perbedaan tingkat keparahan psoriasis kelompok dengan dan tanpa fokal infeksi pada seluruh responden

\begin{tabular}{ccccccccc}
\hline & n & $\begin{array}{c}\text { Rerata } \\
\text { PASI }\end{array}$ & $\begin{array}{c}\text { Shapiro- } \\
\text { Wilk } \text { - } \\
\text { value }\end{array}$ & $\begin{array}{c}\text { Levene } \\
\text { p-value }\end{array}$ & t & $\begin{array}{c}\text { Sig } \\
(2- \\
\text { tailed })\end{array}$ & $\begin{array}{c}\text { Perbedaan } \\
\text { Rerata }\end{array}$ & 95\% IK \\
\hline $\begin{array}{c}\text { Kelompok } \\
\text { dengan }\end{array}$ & 20 & 28,6300 & & & & & & \\
$\begin{array}{c}\text { Fokal } \\
\text { Infeksi }\end{array}$ & & & & & & & \\
$\begin{array}{c}\text { Kelompok } \\
\text { tanpa }\end{array}$ & & & 0,076 & 0,214 & 4,425 & 0,000 & 11,34000 & $6,15165-$ \\
$\quad$ Fokal & 20 & 17,2900 & & & & & & 16,52835 \\
Infeksi & & & & & & & & \\
\hline
\end{tabular}

Sumber: data primer terolah

Uji Shapiro-Wilk dilakukan untuk mengetahui normalitas data penelitian. Hasil uji normalitas data menggunakan uji Shapiro-Wilk menunjukkan bahwa distribusi nilai PASI pada kelompok dengan fokal infeksi dan tanpa fokal infeksi adalah normal karena ShapiroWilk $p$-value lebih besar dari 0,05 . 
Homogenitas variansi diketahui dengan melakukan uji Levene. Uji Levene berdasarkan tabel di atas menunjukkan bahwa variansi data tidak memiliki perbedaan atau homogen ( $p$-value $=0,214)$. Setelah melihat hasil uji Levene, pembacaan hasil uji t dilakukan untuk melihat adanya perbedaan tingkat keparahan kelompok psoriasis dengan dan tanpa fokal infeksi.

Hasil analisis independent t-test menunjukkan terdapat 20 responden dengan fokal infeksi yang memiliki rata-rata nilai PASI sebesar 28,63 dan 20 responden tanpa fokal infeksi memiliki rata-rata nilai PASI sebesar 17,29. Perbedaan rerata adalah sebesar 11,34 dan nilai interval kepercayaan $95 \%$ adalah antara 6,15165 sampai 16,52835 . Dari hasil uji statistik dapat disimpulkan bahwa terdapat perbedaan bermakna antara nilai PASI dari kelompok responden dengan dan tanpa fokal infeksi $(p$-value $=0,000)$.

Analisis bivariat yang digunakan adalah independent t-test. Uji normalitas data dengan uji Shapiro-Wilk dan uji variansi dengan uji Levene dilakukan sebelum analisis bivariat dengan independent t-test. Hasil uji normalitas data adalah data terdistribusi normal dan hasil uji variansi didapatkan data homogen. Hasil independent t-test untuk melihat perbedaan tingkat keparahan psoriasis pada kelompok dengan fokal infeksi dan tanpa fokal infeksi didapatkan nilai p 0,000 yang berarti terdapat perbedaan bermakna tingkat keparahan psoriasis pada kelompok dengan dan tanpa fokal infeksi. Hasil ini sesuai dengan penelitian Picciani et al (2013) yang menyebutkan bahwa terdapat korelasi antara tingkat keparahan psoriasis dan adanya kandidiasis oral yang merupakan salah satu fokal infeksi. Selain itu hasil penelitian ini juga sesuai dengan penelitian Waldman et al (2001) yang menyatakan bahwa responden dengan tingkat keparahan psoriasis berat dua kali lipat lebih banyak yang memiliki kandidiasis oral lebih daripada tidak memiliki kandidiasis oral.

Tabel XIII. Perbedaan tingkat keparahan psoriasis kelompok responden laki-laki dengan dan tanpa fokal infeksi

\begin{tabular}{|c|c|c|c|c|c|c|c|c|}
\hline & $\mathbf{n}$ & $\begin{array}{c}\text { Rerata } \\
\text { PASI }\end{array}$ & $\begin{array}{c}\text { Shapiro- } \\
\text { Wilk } p \text { - } \\
\text { value }\end{array}$ & $\begin{array}{l}\text { Levene } \\
p \text {-value }\end{array}$ & $\mathbf{t}$ & $\begin{array}{c}\text { Sig } \\
(2- \\
\text { tailed })\end{array}$ & $\begin{array}{c}\text { Perbedaan } \\
\text { Rerata }\end{array}$ & $\begin{array}{c}95 \% \\
\text { IK }\end{array}$ \\
\hline $\begin{array}{c}\text { Kelompok } \\
\text { dengan Fokal } \\
\text { Infeksi } \\
\text { Kelompok } \\
\text { tanpa Fokal } \\
\text { Infeksi }\end{array}$ & 5 & 29,425 & 0,130 & 0,104 & 2,227 & 0,048 & 12,2850 & $\begin{array}{l}0,1452- \\
24,4248\end{array}$ \\
\hline
\end{tabular}

Sumber: data primer terolah 
Tabel XIV. Perbedaan tingkat keparahan psoriasis kelompok responden perempuan dengan dan tanpa fokal infeksi

\begin{tabular}{|c|c|c|c|c|c|c|c|c|}
\hline & $\mathbf{n}$ & $\begin{array}{c}\text { Rerata } \\
\text { PASI }\end{array}$ & $\begin{array}{c}\text { Shapiro- } \\
\text { Wilk p- } \\
\text { value }\end{array}$ & $\begin{array}{l}\text { Levene } \\
p \text {-value }\end{array}$ & $\mathrm{t}$ & $\begin{array}{l}\text { Sig } \\
(2- \\
\text { tailed })\end{array}$ & $\begin{array}{c}\text { Perbedaan } \\
\text { Rerata }\end{array}$ & $95 \%$ IK \\
\hline $\begin{array}{l}\text { Kelompok } \\
\text { dengan } \\
\text { Fokal }\end{array}$ & 12 & 28,100 & & & & & & \\
\hline $\begin{array}{l}\text { Infeksi } \\
\text { Kelompok } \\
\text { tanpa Fokal } \\
\text { Infeksi }\end{array}$ & 15 & 17,340 & 0,224 & 0,593 & 3,638 & 0,001 & 10,7600 & $\begin{array}{c}16,8511- \\
16,6983\end{array}$ \\
\hline
\end{tabular}

Sumber: data primer terolah

Hasil analisis independent t-test untuk melihat perbedaan tingkat keparahan psoriasis pada responden laki-laki dengan fokal infeksi dan tanpa fokal infeksi menunjukkan bahwa terdapat 8 responden laki-laki dengan fokal infeksi yang memiliki rata-rata nilai PASI sebesar 29,42 dan 5 responden psoriasis tanpa fokal infeksi memiliki rata-rata nilai PASI sebesar 17,14. Dari hasil uji statistik tersebut dapat disimpulkan bahwa terdapat perbedaan bermakna antara nilai PASI dari kelompok responden laki-laki dengan fokal infeksi dan tanpa fokal infeksi ( $p$-value $=0,048$ ). Pada analisis independent $t$-test responden perempuan menunjukkan bahwa terdapat 12 responden perempuan dengan fokal infeksi yang memiliki rata-rata nilai PASI sebesar 28,10 dan 15 responden psoriasis tanpa fokal infeksi memiliki rata-rata nilai PASI sebesar 17,34. Dari hasil uji statistik tersebut dapat disimpulkan bahwa terdapat perbedaan bermakna antara nilai PASI dari kelompok responden perempuan dengan fokal infeksi dan tanpa fokal infeksi $(p$-value $=0,001)$.

Penelitian terkait perbedaan tingkat keparahan psoriasis pada pasien psoriasis laki-laki dan perempuan yang memiliki fokal infeksi dan tidak memiliki fokal infeksi belum terdapat penelitian tersebut dalam lima tahun terakhir berdasarkan telaah literatur yang telah peneliti lakukan. Namun, ada penelitian yang meneliti psoriasis berdasarkan jenis kelamin serta fokal infeksi berdasarkan jenis kelamin.

Hormon perempuan secara signifikan memengaruhi perubahan biologis dan imunologis pada kulit. Tingkat keparahan psoriasis pada pasien perempuan bisa berubahubah sesuai perubahan hormonal karena psoriasis terjadi lebih sering atau lebih parah pada pubertas dan menopause. Hal ini sesuai dengan hasil analisis distribusi usia responden. Psoriasis dan hormon memiliki hubungan yang sangat kuat sehingga estrogen dan progesteron berpotensi bermanfaat pada tata laksana psoriasis (Ceovic et al, 2013). Kadar hormon estrogen yang tinggi memberikan efek inhibisi pada komponen-komponen respon imun, sedangkan kadar estrogen yang rendah memberikan efek stimulasi (Cutolo et al, 2010). Oleh sebab itu, penelitian terdahulu mendukung hasil analisis penelitian ini, bahwa psoriasis lebih banyak pada perempuan.

Menurut Walter et al (2017), fokal infeksi intraoral yang sering ditemukan, yaitu karies gigi, lebih banyak ditemukan pada perempuan daripada laki-laki Perempuan memiliki risiko karies lebih tinggi daripada laki-laki karena komposisi saliva, fluktuasi hormonal, kebiasaan makan, variasi genetik, dan peran sosial dalam keluarga (Martinez-Mier dan Zandona, 2013). 
Perempuan memiliki fluktuasi kadar hormon dan perubahan psikologis pada saat pubertas, menstruasi, dan kehamilan, sehingga memengaruhi komposisi saliva dan laju saliva secara keseluruhan. Perubahan-perubahan ini mengubah lingkungan oral menjadi lebih kariogenik pada perempuan daripada laki-laki. Hasil penelitian tersebut didukung oleh penelitian Pani dan Al Odhaib (2013) yang menyebutkan bahwa terdapat hubungan karies dengan kadar kortisol saliva. Kortisol merupakan hasil aktivasi aksis hipotalamus-hipofisis-adrenal akibat adanya stres (Wallas et al, 2017). Pasien psoriasis memiliki kecenderungan stres dan kadar kortisol saliva yang tinggi (Pani dan Al Odhaib, 2013). Menurut penelitian Wallas et al (2017), kadar kortisol dalam saliva lebih tinggi secara signifikan pada perempuan daripada laki-laki. Selain kadar kortisol, tingkat stres dapat tercermin pada nilai indeks kualitas hidup pasien. Penelitian Moradi et al (2015) menyatakan bahwa kualitas hidup pasien psoriasis lebih baik pada laki-laki (DLQI 11) daripada perempuan (DLQI 7).

Perbedaan nilai PASI kelompok responden perempuan dengan fokal infeksi dan tanpa fokal infeksi ( $p$-value $=0,001)$ lebih berbeda signifikan daripada perbedaan nilai PASI kelompok responden laki-laki dengan fokal infeksi dan tanpa fokal infeksi $(p$-value $=0,048)$ karena perempuan memiliki komposisi saliva, fluktuasi hormonal, kebiasaan makan, variasi genetik, dan peran sosial dalam keluarga yang berbeda dengan laki-laki, sehingga perempuan lebih memiliki kecenderungan fokal infeksi intraoral (karies) daripada laki-laki.

\section{KESIMPULAN}

Terdapat perbedaan signifikan tingkat keparahan psoriasis pada pasien dengan dan tanpa fokal infeksi di RSUD Prof. Dr. Margono Soekarjo. Rata-rata tingkat keparahan psoriasis pada pasien dengan fokal infeksi 28,63 dan tanpa fokal infeksi 17,29. Jenis fokal infeksi didapatkan fokal infeksi intraoral $(47,5 \%)$ dan genital $(2,5 \%)$.

\section{UCAPAN TERIMA KASIH}

Penulis mengucapkan terima kasih kepada Fakultas Kedokteran, Universitas Jenderal Soedirman, Purwokerto dan RSUD. Prof. Dr. Margono Soekarjo, Purwokerto.

\section{DAFTAR PUSTAKA}

Bellagambi, F.G., I. Degano, S. Ghimenti, T. Lomonaco, V. Dini, M. Romanelli, F. Mastorci, A. Gemignani, P. Salvo, R. Fuoco, F. Di Francesco. 2018. Determination of salivary $\alpha-$ amylase and cortisol in psoriatic subjects undergoing the Trier Social Stress Test. Microchem J 136: 177-184.

Brzewski, P.L., M. Spalkowska, M. Podbielska, J. Chmielewska, M. Wolek, K. Malec, A.WojasPelc. 2013. The role of focal infections in the pathogenesis of psoriasis and chronic urticaria. Postep Derm Alergol XXX, 2: 77-84.

Budiastuti, A. 2011. Korelasi Kadar TNF- $\alpha$ dan Skor Psoriasis Area and Severity Index (PASI) pada Pasien Psoriasis. Media Medika Indonesiana 45 (2): 133-137.

Ceovic, R., M. Mance, Z.B. Mokos, M. Svetec, K. Kostovic, D.S. Buzina. 2013. Psoriasis: female skin changes in various hormonal stages throughout life- puberty, pregnancy, and menopause. BioMed Research International 2013: 1-6. 
Cutolo, M., R. Brizzolara, F. Atzeni, S. Capellino, R.H. Straub, P.C.S. Puttini. 2010. The immunomodulatory effects of estrogens: clinical relevance in immune-mediated rheumatic diseases. Annals of the New York Academy of Sciences 1193: 36-42.

Ernawati, L. 2017. Komunikasi Pribadi, Rekam Medik, Rumah Sakit Umum Daerah Prof. Dr. Margono Soekarjo, Purwokerto.

Gayatri, L., dan E. Ervianti. 2014. Studi restrospektif: psoriasis pustulosa generalisata. Berkala Ilmu Kesehatan Kulit dan Kelamin 26(1): 48-55.

Gudjonsson, J.E. dan J.T. Elder. 2012. Chapter 18: Psoriasis. Hal. 169-193. Dalam: G.S. Katz, B.G. Paller, K. Wolff (Editors.) Fitzpatrick Dermatology in General Medicine. $8^{\text {th }}$ ed. New York: McGraw-Hill.

Jacoeb, T.N.A. 2003. Psoriasis: Gambaran klinis dan penilaian keparahan. Hal. 1-13. Dalam: A. Tjarta, A. Sularsito, D.D. Kurniati, R. Rihatmaja (Editors.) Metode Diagnostik dan Penatalaksanaan Psoriasis dan Dermatitis Seboroik. Jakarta: FK UI.

Khanna, N. dan A.S. Kumar. 2015. World Clinics Dermatology. New Delhi: Jaypee The Health Sciences Publisher.

Martinez-Mier, E.A. dan A.F. Zandona. 2013. The impact of gender on caries prevalence and risk assessment. Dent Clin N Am 57: 301-315.

Moradi, M. F. Rencz, V. Brodszky, A. Moradi, O. Balogh, L. Gulácsi. 2015. Health status and quality of life in patients with psoriasis: an Iranian cross-sectional survey. Arch Iran Med 18(3): 153-159.

Pani, S.C. dan M. Al Odhaib. 2013. The impact of dental treatment on the salivary cortisol levels of children with severe early childhood caries. Eur Arch Paediatr Dent 14: 307-312.

Picciani, B.L.S., B. Michalski-Santos, S. Carneiro, A.L. Sampaio, J.C.R. Avelleira, D.R. Azulay, J.M.N. Pinto, E.P. Dias. 2013. Oral candidiasis in patients with psoriasis: Correlation of oral examination and cytopathological evaluation with psoriasis disease severity and treatment. J Am Acad Dermatol 68(6): 986-991.

Waldman, A., A. Gilhar, L. Duek, I. Berdicevsky. 2001. Incidence of Candida in psoriasis-a study on the fungal flora of psoriatic patients. Mycoses 44(3-4): 77-81.

Wallas, A., C. Eriksson, O. Gruzieva, T. Lind, A. Pyko, M. Sjöström, M. Ögren, G. Pershagen. 2017. Road traffic noise and determinants of saliva cortisol levels among adolescents. Int J Hyg Environ Health 17: 30135-30139.

Walter, B.S., S.N. DeWitte, R.C. Redfern. 2016. Sex differentials in caries frequencies in Medieval London. Arch Oral Biol 63: 32-39. 
World Health Organization. 2016. Global report on psoriasis. Switzerland: World Health Organization. 